\title{
A “descrição pictural” como ato de transgressão nos diários de Nathaniel Hawthorne
}

\author{
Geraldo Magela Cáffaro \\ Universidade Federal de Minas Gerais
}

\begin{abstract}
RESUMO
Este texto explora situações de transgressão do real nos diários de Nathaniel Hawthorne. Como tais situações encontram-se ligadas à evocação da pintura, utiliza-se o conceito de “descrição pictural” de Liliane Louvel na presente discussão. Assim, o aspecto criativo do diário é aqui enfatizado em detrimento do aspecto mimético.
\end{abstract}

\section{PALAVRAS-CHAVE}

Descrição pictural, transgressão, mimésis, diários, Hawthorne

O diário de escritor tem atraído a atenção de pesquisadores em diversas áreas da crítica literária. Grande parte dos trabalhos sobre diários, no entanto, encontra-se circunscrita ao eixo crítica biográfica/crítica genética, cuja abordagem reserva um papel nitidamente secundário a esses objetos (no primeiro caso, os diários servem de fonte ou suporte para estudos sobre a biografia do autor, enquanto no segundo o interesse recai sobre os processos de concepção da obra literária aí presentes). Assim, estudos que abordam o diário como corpus primário e que tentam explorar o tipo de escrita que esse objeto engendra são poucos. ${ }^{1}$ Essa é a direção que o presente estudo deve seguir. Ele parte de uma questão de interesse geral para a literatura - a mimésis - para a análise de um caso específico: o dos diários do escritor americano Nathaniel Hawthorne.

Uma vez que o diário se encontra em estreita relação com o vivido, poder-se-ia pensar que esse seria um modo de escrita mais mimético e transparente, no qual não haveria semiosis. Essa parece ser a visão de alguns teóricos do gênero, além de estar consagrada no senso comum. Em contrapartida, gostaria de levantar a hipótese de que os diários de

\footnotetext{
${ }^{1}$ Ainda assim, vale mencionar a coletânea de ensaios de Philippe Lejeune On Diary (2009), que apresenta estudos vastos e detalhados da escrita diarística em diversos âmbitos.
} 
Hawthorne transgridem o real ao estabelecer um diálogo com a pintura. O desenvolvimento de tal hipótese deverá, em primeiro lugar, situar o diário de Hawthorne em seu contexto histórico e cultural; em seguida, o conceito de transgressão de Wolfgang Iser - que dá sustentação à hipótese - deverá ser explicitado. Finalmente, trechos dos diários serão analisados sob a luz de Iser e do conceito de “descrição pictural” de Liliane Louvel.

Os diários² de Hawthorne (1804-1864) fazem parte de uma tradição excursionista típica do período romântico. No final do século 18 e início do 19, a natureza passou a ter uma importância cada vez maior para poetas e artistas de forma geral, e escritores como Wordsworth e Coleridge empreenderam diversas viagens pelo interior de seu país com o objetivo de observar e retratar paisagens não urbanas. Hawthorne, assim como seus conterrâneos Emerson e Thoreau, continuaram a tradição nos Estados Unidos, narrando e descrevendo suas experiências de forma profusa em seus cadernos e diários.

Uma característica marcante das descrições de paisagens em Coleridge, Thoreau e Hawthorne é a evocação da pintura ou até mesmo a tentativa de "pintar” com palavras a cena observada. Essa tendência remonta ao turismo pitoresco de William Gilpin, que procurava na natureza as qualidades visuais que seriam apropriadas à pintura. Por influência de Gilpin, em meados do século 18 o termo pitoresco já fazia parte do vocabulário não só da literatura, mas também da arquitetura e paisagismo, produzindo teóricos em suas respectivas áreas. Como observa Marshall, nesse período “a prática de ver o mundo através da perspectiva da arte ganha força e autoridade em uma crescente rejeição da arte, da artificialidade, e do artifício, e especialmente na vinculação paradoxal da natureza à experiência estética”. ${ }^{3}$

De que forma, então, essa “vinculação da natureza à experiência estética” se constitui em transgressão nos diários de Hawthorne? Primeiramente, devemos nos ater à ideia de transgressão do real apresentada por Iser em seu $O$ fictício e o imaginário: mapeando a antropologia literária. Para o autor, “o texto literário é uma mistura de realidade e ficções, e

\footnotetext{
${ }^{2}$ Refiro-me, neste trabalho, apenas aos Diários americanos do autor. Os outros dois volumes são os Diários ingleses e os Diários franceses e italianos, nomeados de acordo com o lugar de composição. Os Diários ingleses consistem principalmente de observações da vida e costumes ingleses e serviram como base para a coleção de ensaios Our Old Home. Os Diários franceses e italianos compreendem o grand tour de Hawthorne pela França e Itália, e também são caracterizados pelo interesse nas culturas locais. Na Europa, Hawthorne já era uma figura pública (tendo sido nomeado como cônsul dos Estados Unidos em Liverpool) e suas anotações refletem essa mudança de posição. Por isso, os Diários americanos parecem ter sido negligenciados em estudos sobre o autor, o que justifica sua escolha como corpus nesse trabalho.

${ }^{3}$ MARSHALL. The Problem of the Picturesque, p. 416. (tradução nossa)
} 
dessa forma, ele resulta em uma interação entre o dado e o imaginado”. " Contudo, a partir do momento em que essa interação é estabelecida, o dado ou real não pode mais ser identificado com o sistema do qual ele foi retirado, já que "ele se torna signo de outra coisa”. 5 Está configurada, assim, uma transgressão. Esse ato de transgressão de fronteiras (act of boundarycrossing) é o resultado da operação do fictício, que é descrito como um “ato intencional”, e não como sinônimo de invenção, irrealidade ou mentira. Por meio do fictício, elementos de diferentes campos de referência (por exemplo, o campo identificado com o real empírico observado pelo escritor, o campo da pintura, e o campo da literatura) passam a fazer parte de um mesmo espaço simbólico, que por sua vez constitui um outro campo de referência.

Entre os três atos de transgressão classificados por Iser, dois têm relevância para o presente estudo: a seleção e a combinação. O conceito de seleção se aproxima muito do próprio conceito de fictício ou de ato de transgressão. Ainda assim, a formulação do autor deve ser observada:

Todo texto literário inevitavelmente contém seleção de uma variedade de sistemas socio-historico-culturais, que existem como campos referenciais fora do texto. Essa seleção é em si mesma uma transgressão de fronteiras, na qual os elementos selecionados são deslocados dos sistemas nos quais exerciam suas funções específicas. ${ }^{6}$

A partir desse conceito, podemos examinar como ocorre seleção nos diários em questão.

Ao observar uma das diversas paisagens outonais presentes em seus diários americanos, Hawthorne descreve:

(...) there were some trees that seemed really made of sunshine, and others of a sunny red, and the whole picture was painted with but little relief of darksome hues - only a few evergreens. But there was nothing inharmonious; and, on closer examination, it appeared that all the hues had a relationship among themselves; and this, I suppose, is the reason, that, while Nature seems to scatter them so carelessly, they still never shock the beholder by their contrasts, nor disturb, but only soothe. The brilliant yellow, and the brilliant scarlet, are different hues of the maple leaves, and the first changes into the last. I saw one maple-tree, its centre yellow as gold, set in a frame-work of red. ${ }^{7}$

\footnotetext{
${ }^{4}$ ISER. The Fictive and the Imaginary: Charting Literary Anthropology, p. 1. (Todas as citações de Iser são traduções nossas.)

${ }^{5}$ ISER. The Fictive and the Imaginary: Charting Literary Anthropology, p. 3.

${ }^{6}$ ISER. The Fictive and the Imaginary: Charting Literary Anthropology, p. 5.

${ }^{7}$ HAWTHORNE. The American Notebooks, p. 212. (Os grifos nesse trecho são nossos.)
} 
Percebe-se, nesse trecho, que longe de representar o referente de forma mimética, o diarista opta por apresentá-lo como se esse fosse uma pintura. Consequentemente, o objeto natural perde a sua naturalidade e é visto como um objeto feito pelo homem. Ao mesmo tempo, a pintura é descrita como se fosse inerente à natureza. Dessa forma, dois sistemas referenciais diferentes (a pintura e o mundo natural) são justapostos e ganham novos sentidos na interação. Mas a relação estabelecida não é apenas entre pintura e natureza, mas também entre o verbal (a descrição) e o visual (a evocação à pintura).

Se esse trecho ilustra bem o ato de seleção, ele não é menos adequado a uma análise do ato de combinação. Nesse caso, como explica Iser:

O significado lexical de uma dada palavra se apaga e um novo sentido é realçado, sem a perda do sentido original. Isso estabelece uma relação figura-fundo que permite tanto a separação dos elementos individuais quanto uma contínua alternância de perspectiva entre eles. ${ }^{8}$

Portanto, quando Hawthorne escreve "the whole picture was painted with but little relief of darksome hues”, ele está utilizando o significado metafórico desse léxico, já que a paisagem não é de fato uma pintura.

Outros exemplos de combinação ocorrem quando o escritor retrata objetos naturais e inanimados como se esses estivessem vestidos, como no trecho a seguir:

I must mention again the very beautiful effect produced by the masses of blueberry bushes (or whortle-berry) lying like scarlet islands in the midst of withered pasture-ground, or crowning the tops of barren hills. Their hue, at a distance, is a lustrous scarlet; although it does not look nearly so bright and beautiful, when examined close at hand. But, at a proper distance, it's a beautiful fringe on Autumn's petticoat. ${ }^{9}$

Aqui, “Autumn” é o elemento personificado, e "petticoat”, ou anágua, a figura que indica o ato de combinação. Por conseguinte, o sentido denotativo de "petticoat” passa para o segundo plano, abrindo caminho para uma apreciação dos elementos observados como objetos vivos e estéticos.

Como nosso interesse se concentra especificamente na relação entre texto e imagem evidenciada como recorrente no corpus escolhido para este trabalho, devemos passar agora à análise de mais referências à pintura nos diários, sob outro prisma. O efeito dessas referências ainda será rearticulado com a ideia de transgressão ao longo da discussão de alguns trechos. Para analisar tais referências, o conceito utilizado será o de “descrição pictural” de Liliane

\footnotetext{
${ }^{8}$ ISER. The Fictive and the Imaginary: Charting Literary Anthropology, p. 7.

${ }^{9}$ HAWTHORNE. The American Notebooks, p. 220. (grifo nosso)
} 
Louvel, como havia antecipado. Esse conceito fornecerá um parâmetro coerente para se tratar da analogia entre imagem e texto a partir do próprio texto, sem o recurso a elementos externos e subjetivos.

Em "Nuances du pictural”, a autora define "pictural” como "o surgimento de uma referência às artes visuais em um texto literário, sob formas mais ou menos explícitas, com valor de citação, produzindo um efeito de metapicturalidade textual”. ${ }^{10}$ Logo a seguir, ela transcreve a definição de Viola Winner, para quem a descrição pictural é "a prática que consiste em descrever pessoas, lugares, cenas, como se fossem quadros de pintura, ou temas de quadros, e a utilização de objetos estéticos para enfatizar os desenvolvimentos temáticos”. ${ }^{11}$ Embora Louvel condene o uso da expressão como se, que poderia levar a abordagens subjetivas, ambas as definições serão mantidas em perspectiva para a análise que se segue.

Contudo, será necessário recorrer aos marcadores de picturalidade classificados por Louvel nesse mesmo texto para identificar exemplos de descrição pictural. Esses marcadores são:

(...) léxico técnico (cores, nuanças, perspectiva, glacis, verniz, formas, camadas, linha, etc.); a referência aos gêneros picturais (natureza-morta, retrato, marinha); o recurso dos efeitos de enquadramento; a colocação de operadores de abertura e de fechamento da descrição pictural (dêiticos, enquadramentos textuais como as narrativas encaixadas, a pontuação, o branco tipográfico, a repetição do motivo “era”); a colocação de focalizadores e operadores de visão; a concentração na estória de dispositivos técnicos que permitem ver; o recurso das comparações explícitas - "como em um quadro"; a suspensão do tempo marcado pela forma -ing em inglês(...). ${ }^{12}$

Primeiramente, vejamos como o léxico técnico é utilizado por Hawthorne na passagem abaixo:

Last evening, on a walk, Graylock and the whole of Saddleback was at first tinged with a mild, half-sunshine tinge; then it grew almost black - a huge mass, lying on the back of the earth, and encumbering it. Stretching up from behind the back mountain, over a third or more of the sky, there was a heavy, somber blue mass or ledge of clouds - looking almost as solid as rock. The volumes, of which it was composed, were perceptible by lines and fissures being translucent; but the mass, as a whole, seemed as solid,

\footnotetext{
${ }^{10}$ LOUVEL. Nuances du pictural, p. 175. Tradução de Márcia Arbex inédita.

${ }^{11}$ LOUVEL. Nuances du pictural, p. 175. Tradução de Márcia Arbex inédita.

${ }^{12}$ LOUVEL. Nuances du pictural, p. 177. Tradução de Márcia Arbex inédita
} 
voluminous, and ponderous in the cloud world, as the mountain was on earth. ${ }^{13}$

Naturalmente, a ideia de composição que é transmitida nessa entrada não é inerente à paisagem, mas é projetada nela pelo autor. Por isso, apesar da referência ao que supomos serem lugares reais (Grayock e Saddleback), esse real é transgredido na forma como ele é retratado no trecho. E essa transgressão, como podemos ver nas palavras em itálico, ocorre por meio da “descrição pictural”.

Uma outra entrada em que ocorre o uso de léxico técnico (com ênfase especial nas cores) é transcrita a seguir:

The woods present a very diversified appearance, just now, with perhaps more varieties of tint, though less marked ones, than they are destined to wear at a somewhat later period. There are some strong yellow hues, and some deep red; there are innumerable shades of green; some few having the depth of summer; others, partially changed towards yellow, look freshly verdant, the delicate tinge of early summer, or of May. Then there is the solemn dark green of the pines. The effect is, that every tree in the wood, and every bush among the shrubbery, seems to have a separate existence, since, confusedly intermingled, each wears its peculiar hue, instead of being lost in the universal verdure of the summer. And yet there is $a$ oneness of effect, likewise, when we choose to look at a whole sweep of woodland, or swamp shrubbery, instead of analyzing its component trees. ${ }^{14}$

Aqui, quatro diferentes sinônimos para cor são usados, o que sugere uma intenção estética ou metapictural por parte do diarista. Além disso, é interessante notar que nessa entrada as cores não são utilizadas meramente como qualificadoras de substantivos, mas aparecem como núcleos de seus sintagmas nominais: some deep red, shades of green. Por outro lado, as expressões oneness of effect e to look at a whole sweep of woodland também podem ser vistas como marcadores de picturalidade nessa descrição, imobilizando a cena e dando ao leitor uma sensação de unidade visual que normalmente se associa à pintura.

Tais expressões também apontam para um sujeito observador e para um ponto de vista particular de onde ele olha a paisagem. De fato, podem-se relacionar tais expressões ao que Louvel chama de "focalizadores e operadores de visão". Nos diários americanos de Hawthorne, diversos outros operadores do mesmo tipo lembram o leitor do inelutável ato de ver anterior à realidade representada e da perspectiva que produz, e não apenas registra essa mesma realidade. Examinemos outra entrada em que o verbo see e a expressão at a distance exercem tal papel:

\footnotetext{
${ }^{13}$ HAWTHORNE. The American Notebooks, p. 137. (grifos nossos com exceção de "ledges”.)

${ }^{14}$ HAWTHORNE. The American Notebooks, p. 206-207.(grifos nossos)
} 
(...) I saw also a long flat-bottomed boat go up the river, with a brisk wind and against a strong stream. Its sails were of curious construction; a long mast, with two sails below, one on each side of the boat, and a broader one surmounting them. The sails were colored brown and looked like leather, or skins, but were really cloth; at a distance, the vessel looked like, or at least I compared it to, a monstrous water insect, skimming along the river. If the sails had been crimson, yellow \&c, the resemblance would have been much better. $^{15}$

Os focalizadores destacados acima nos ajudam a criar uma imagem mental da cena da forma como ela foi vista pelo escritor, mas eles também o permitem ir além da mimésis pura. As últimas quatro linhas mostram uma lacuna entre a realidade concreta e o que é possível apreender dela. Desta vez, podemos ver a operação do fictício (ou ato de transgressão) em sua origem: se o escritor não tivesse utilizado as expressões looked like e I compared it to, ao invés de uma comparação, nós teríamos uma metáfora. Porém, a imagem do "monstruoso inseto aquático" se torna parte do horizonte visual da descrição, assim como acontece com as cores que tornariam a semelhança ainda mais vívida. A distância, assim, não é apenas um veículo para a produção de um efeito pictural, mas é também um meio pelo qual a diferença se manifesta.

Se os indicadores de picturalidade analisados acima não são inequívocos o suficiente para considerarmos tais entradas como descrições picturais, o fragmento abaixo fornece uma ilustração definitiva de tal procedimento. Em 9 de Maio de 1845, Hawthorne escreve: "Towards the dimness of evening, a half-length figure appearing at a window: - the blackness of the back ground and the light upon the face cause it to appear like a Rembrandt picture.”16 Não se pode saber se essa entrada foi resultado de uma ocorrência real ou se foi simplesmente produto da imaginação do escritor. O que está em jogo, por outro lado, é o número de marcadores picturais que se pode identificar nesse trecho. Primeiramente, a janela funciona como um dispositivo de enquadramento, conferindo à cena os limites necessários para que ela seja vista como uma pintura. Em segundo lugar, o diarista usa o que podem ser considerados como termos técnicos da pintura: “background” e “light”. A forma -ing em “appearing” é um indicador adicional da picturalidade da descrição, embora ela sugira uma tensão entre a ação e a suspensão da própria ação. Não menos importante é a comparação entre a cena e um quadro de Rembrandt, introduzida pelo comparativo. Por extensão, como o nome do pintor é mencionado, podemos falar de intertextualidade, e consequentemente de seleção com relação a essa entrada (ou seja, a justaposição de elementos de diferentes campos referenciais).

\footnotetext{
${ }^{15}$ HAWTHORNE. The American Notebooks, p. 47. (grifos nossos)

${ }^{16}$ HAWTHORNE. The American Notebooks, p. 259.
} 
Podemos concluir que as descrições picturais nos diários de Hawthorne funcionam como recursos semióticos, buscando uma aproximação entre o visual e o verbal e atribuindo qualidades pictóricas às paisagens. De fato, de acordo com Louvel:

O iconotexto ${ }^{17}$ não estaria mais numa situação de ancoragem do real, mas estaria duplamente desligado, passando a evoluir no centro da representação e não mais num sistema normativo, em que o plano da representação entra ainda em interseção com o plano da realidade. Não se trata mais de uma relação significante/significado, mas da relação significante/significante/significado. ${ }^{18}$

O argumento de Louvel corrobora a hipótese que propus no início deste trabalho. Se o filtro pictural se interpõe entre a realidade e a representação da realidade, então o que se tem é menos um reflexo do que uma manipulação do referente, o que leva a uma transgressão de fronteiras no sentido de Iser. As instâncias de transgressão analisadas aqui são sinalizadas tanto pela combinação quanto pela seleção, operações em que os signos são deslocados e perspectivizados ao serem colocados em relações com signos de outros contextos.

Se essa transgressão nos permite ver o diário com outros olhos é porque ela desmistifica generalizações a respeito do gênero baseadas em uma ideia de transparência do registro diarístico. Do ponto de vista teórico, o conceito de Iser nos permite um novo aporte das categorias do real e do fictício em que elas não se encontram em oposição binária como verdade/mentira, sendo que o fictício é concebido como um ato intencional e não um campo referencial. Como pudemos ver, o diário oferece material suficiente para análises textuais (e não somente comprobatórias) que considerem o seu valor retórico, e por que não, literário. Por sua vez, tais análises promovem uma abertura do texto à história e a outras artes, como o caso de Hawthorne ilustra bem.

\section{ABSTRACT}

This text explores instances of overstepping in Nathaniel Hawthorne's diaries. Since such instances are associated with the evocation of painting, we adopt the concept of "pictural description" by Liliane Louvel in the present discussion. Thus, the creative aspect of the diary is here emphasized in detriment to the mimetic aspect.

\footnotetext{
${ }^{17} \mathrm{O}$ conceito de iconotexto de Louvel abrange "a presença de uma imagem visual convocada pelo texto e não somente utilização de uma imagem visível para ilustração ou como ponto de partida criativo”. LOUVEL. A “descrição pictural”: por uma poética do iconotexto, p. 218.

${ }^{18}$ LOUVEL. A “descrição pictural”: por uma poética do iconotexto, p. 193.
} 


\section{KEYWORDS}

Pictural description, boundary-crossing, mimésis, private journals, Hawthorne

\section{REFERÊNCIAS}

HAWTHORNE, Nathaniel. The American Notebooks. Ed. Claude M. Simpson. Ohio State University Press, 1932.

ISER, Wolfgang. The Fictive and the Imaginary: Charting Literary Anthropology. Baltimore: The Johns Hopkins University Press, 1993.

LEJEUNE, Philippe. On Diary. Trad. Katherine Durnin. Honolulu: University of Hawai'I Press, 2009.

LOUVEL, Liliane. Nuances du pictural. Poétique, n. 126. Paris: Seuil, avr. 2001.

LOUVEL, Liliane. A “descrição pictural”: por uma poética do iconotexto. In: ARBEX, Márcia (Org.). Poéticas do visível: ensaios sobre a escrita e a imagem. Belo Horizonte: Faculdade de Letras da UFMG, Programa de Pós-Graduação em Letras: Estudos Literários, 2006.

MARSHALL, David. The problem of the picturesque. Eighteenth-Century Studies, v. 35, n. 3, p. 412-37, 2002. 